\title{
A Literature Review of Dorsal Root Entry Zone Complex (DREZC) Lesions: Integration of Translational Data for an Evolution to More Accurate Nomenclature
}

\section{Ognjen Visnjevac iD ${ }^{1-3}$ Frederick $\mathrm{Ma}$ iD $^{3}$ Alaa Abd-Elsayed ${ }^{4}$ \\ 'Department of Anesthesia, Faculty of Health Sciences, McMaster University, Hamilton, Ontario, Canada; ${ }^{2}$ Cleveland Clinic Canada, Toronto, Ontario, Canada; ${ }^{3}$ Spine Pain Program, Bloor Pain Specialists, Toronto, Ontario, Canada; ${ }^{4}$ Department of Anesthesiology, University of Wisconsin School of Medicine and Public Health, Madison, WI, USA}

\section{Video Abstract}

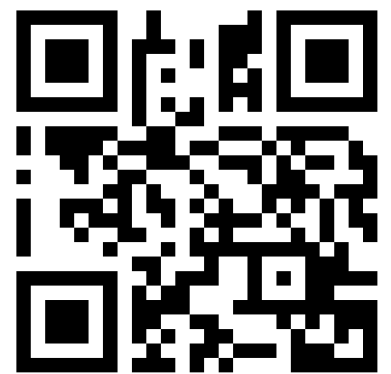

Point your SmartPhone at the code above. If you have a $Q R$ code reader the video abstract will appear. Or use: https://youtu.be/BVBDOHy-eAl.

Correspondence: Ognjen Visnjevac Email ovisnjevac@yahoo.com
This article was published in the following Dove Press journal:

Journal of Pain Research

\begin{abstract}
The purpose of this translational review was to provide evidence to support the natural evolution of the nomenclature of neuromodulatory and neuroablative radiofrequency lesions for pain management from lesions of individualized components of the linear dorsal afferent pathway to "Dorsal Root Entry Zone Complex (DREZC) lesions." Literature review was performed to collate anatomic and procedural data and correlate these data to clinical outcomes. There is ample evidence that the individual components of the DREZC (the dorsal rami and its branches, the dorsal root ganglia, the dorsal rootlets, and the dorsal root entry zone) vary dramatically between vertebral levels and individual patients. Procedurally, fluoroscopy, the most commonly utilized technology is a 2-dimensional $\mathrm{x}$-ray-based technology without the ability to accurately locate any one component of the DREZC dorsal afferent pathway, which results in clinical inaccuracies when naming each lesion. Despite the inherent anatomic variability and these procedural limitations, the expected poor clinical outcomes that might follow such nomenclature inaccuracies have not been shown to be prominent, likely because these are all lesions of the same anatomically linear sensory pathway, the DREZC, whereby a lesion in any one part of the pathway would be expected to interrupt sensory transmission of pain to all subsequent more proximal segments. Given that the common clinically available tools (fluoroscopy) are inaccurate to localize each component of the DREZC, it would be inappropriate to continue to erroneously refer to these lesions as lesions of individual components, when the more accurate "DREZC lesions" designation can be utilized. Hence, to avoid inaccuracies in nomenclature and until more accurate imaging technology is commonly utilized, the evidence herein supports the proposed change to this more sensitive and inclusive nomenclature, "DREZC lesions."
\end{abstract}

Keywords: pulsed radiofrequency treatment, DREZ, radiofrequency ablation, chronic pain, ganglia, spinal

\section{Introduction}

The objective of this manuscript is to provide evidence for a proposed transition in nomenclature for a milieu of similar pain management procedures to the more accurate and encompassing name, Dorsal Root Entry Zone Complex (DREZC) lesions. Chronic pain is more prevalent in the USA than cancer, cardiac disease, and diabetes combined, affecting over 100 million Americans with a financial burden ranging from $\$ 560$ to $\$ 635$ billion in 2010 US dollars, ${ }^{1}$ and pain management procedures play a major role in the care of these patients. Anatomically, pain transmission is perceived through the 
dorsal afferent pathways, which begin with extraspinal peripheral nerve branches like the medial, intermediate, or lateral branches, which connect to the spinal nerves (SN), and propagate painful signals through the dorsal roots (DR) along the dorsal afferent pathway. The DR then propagate that afferent signal to the dorsal root ganglia (DRG) and, subsequently, to the dorsal rootlets (DRL) and, then, to the dorsal root entry zone (DREZ), herein collectively termed the Dorsal Root Entry Zone Complex (DREZC) (Figure 1). ${ }^{2-7}$

Neuroablative and/or neuromodulatory radiofrequency lesions have been utilized to lesion each of the DREZC components, from the distal branches to the DREZ itself. ${ }^{8-11}$ The
DREZC is a linear conducting system, in which any anatomic or functional lesion in any one component will interrupt the transmission of pain to all subsequent more proximal segments. ${ }^{11-18}$ Thus, we propose a transition of nomenclature to refer to these lesions collectively as, DREZC lesions.

Unfortunately, the nomenclature has been traditionally diverse, identifying lesions of each component of the DREZC as separate procedures, rather than lesions of the same linear DREZC afferent pathway. This is fraught with several fallacies as outlined below. Thus, the objective of this narrative review is to integrate translational data (anatomic and clinical) to support the natural evolution of the

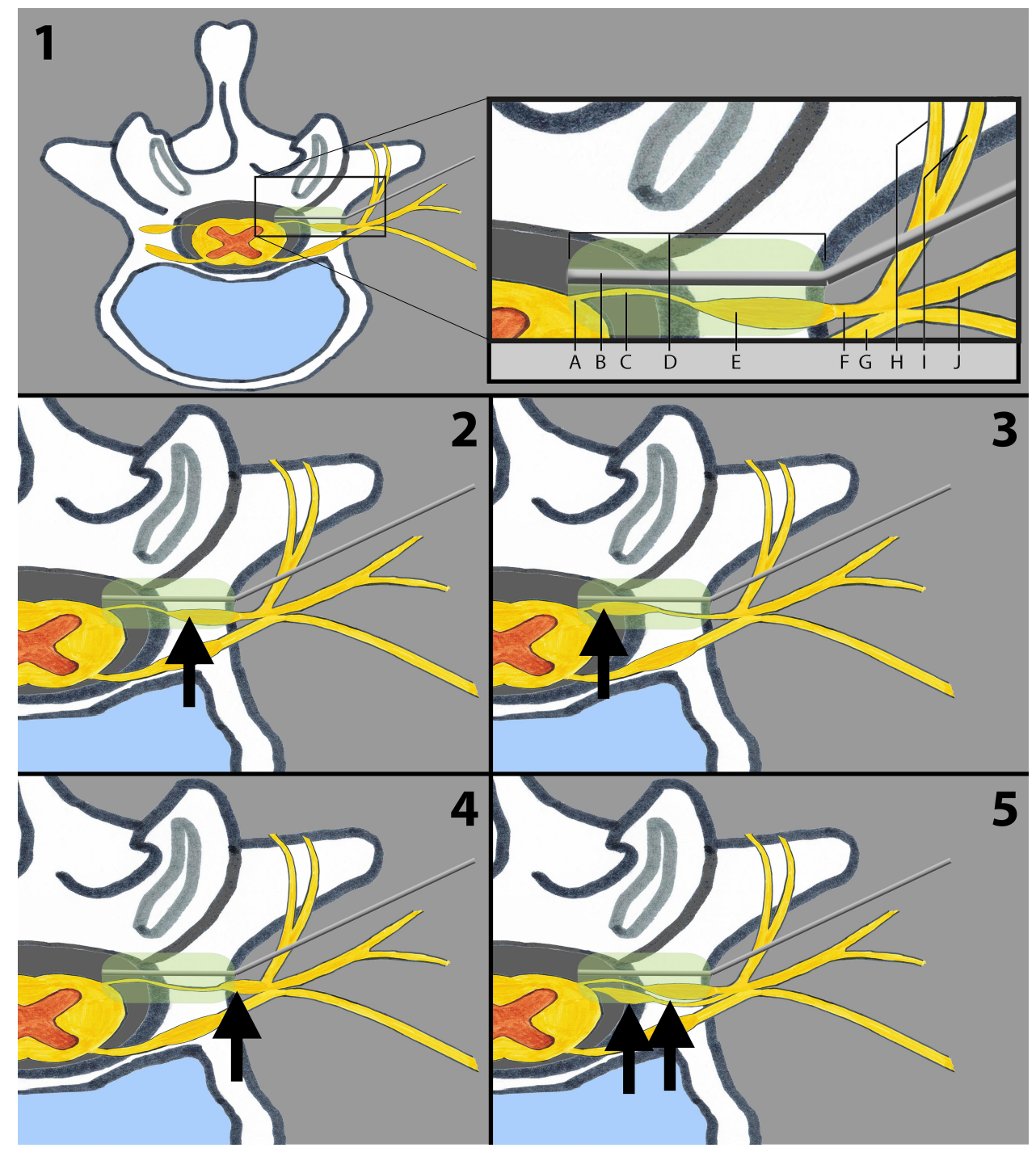

Figure I Schematic of variability of dorsal root entry zone complex (DREZC) anatomy in correlation to typical radiofrequency cannula anatomic position. I. Lumbar vertebra with spinal cord and sensory afferent pathway segments with magnified and labeled view box to the right side. The dorsal root entry zone complex (DREZC) is composed of components labelled A, C, E, and F. A. Dorsal Root Entry Zone (DREZ). B. Radiofrequency (RF) cannula in typical position, adjacent to the DREZC. C. Dorsal Rootlets (DRL). Herein artistically depicted as one line, but DRL can vary in number to as many as I5 DRL per DREZC. D. The anatomic distribution of the energy wave emitted by the RF cannula. E. Dorsal Root Ganglion (DRG). F. Dorsal root (DR). G. Ventral root. H. Medial branch. I. Intermediate branch. J. Lateral branch. $2-5$ show variability in anatomic position and number of DRG relative to the vertebra and RF cannula. Arrow depicts DRG. 2. Intraforaminal DRG anatomy. 3. Intraspinal DRG anatomy. 4. Extraforaminal DRG anatomy. 5. DRG Bigangliar anatomy. 
nomenclature from lesions of individualized components of the DREZC to, henceforth, refer to these neuroablative and/or neuromodulatory radiofrequency lesions of the DREZC as, "DREZC lesions."

\section{Methods}

\section{Search Strategy}

A literature search with PUBMED was carried out with publication date range from inception to March 1, 2020, with the following search terms: "DREZ" (317 reports); ("Ganglia, Spinal"[Mesh]) AND "Spinal Canal"'[Mesh] (22 reports); "dorsal root foraminal anatomy" (146 reports); "dorsal root ganglion foraminal anatomy" (31 reports); "pulsed radiofrequency dorsal root" (142 reports); and "radiofrequency dorsal root ganglion," (187 reports). In addition, bibliographies of retrieved literature were cross-referenced to identify reports omitted from search terms mentioned above. This was not a systematic review, nor was it intended as such. Rather, the purpose of the search was to combine the anatomic data (linear dorsal sensory pathway, of which a lesion at any point would result in a disruption of sensory transmission through the same linear pathway) with clinical data to support or refute the physiologic hypothesis that a lesion of any part of a linear sensory pathway would result in disruption of painful neural sensory transmission.

\section{Inclusion Criteria}

Only English language publications were considered. Those describing anatomic findings relating to components of the DREZC (Figure 1) were considered. Reports related to procedural outcomes relating to lesions of the dorsal afferent pathway were also included. Using the PICOS method, clinical data were considered if they described a population of patient for any pain indication; underwent RF lesioning of any component of the DREZC, regardless of whether or not a comparative treatment was described; and inclusive of all clinical patient outcomes described, both positive and negative. Study type was not limited by study design, although only human data were included.

\section{Exclusion Criteria}

Non-English language publications and animal data were excluded.

\section{Data Collection}

Once duplicate publications were deleted, reports were screened for eligibility. Those with data applicable to the objective described above were utilized. Data that met inclusion and exclusion criteria and were relevant to the Outcomes Measured described below were extracted from these documents by all three authors and collated. Discrepancies in data extracted were resolved through discussion between the authors.

\section{Outcomes Measured}

Anatomic variability data were identified and documented for each segment of the DREZC (Figure 1), including data regarding size, shape, number, and location of each DRG, DR, and VR. Clinical outcomes for neuroablative and/or neuromodulatory procedures involving the DREZC components (Figure 1), both positive and negative, were included when the data were available, with rate of successful analgesia considered as the primary outcome for clinical data, irrespective of how analgesia was measured. Data presenting scales for pain and functional change were considered, but no attempt was made to tabulate or compare scale-based data to the binary data of "success" or "failure" to achieve analgesia post-procedure. No quantifiable analyses were performed or intended.

\section{Results}

A total of 858 studies were found using the search strategy, including reports identified through bibliographic review. Seventy-two were retained for inclusion herein. Publications spanned 1980 to 2019.

\section{Procedural and Anatomic Data}

First, there is significant variability in the anatomy of individual components of the DREZC, not just from individual person to person, but at each spinal level within the same person. The number of DR and DRGs per spinal level have been found to vary from 1 to 3 ipsilateral DRGs per spinal level (Tables 1 and 2). ${ }^{19-21}$ The DRG size has been found to vary between spinal levels as well. ${ }^{22-24}$ Similarly, the locations of DRGs in relation to their respective foraminae -

Table I Analysis of Dorsal and Ventral Root Anatomy at the Intervertebral Foramina (L4 and L5): Singular or Bifurcating ${ }^{19}$

\begin{tabular}{|l|l|}
\hline Number of Roots/Ganglia & n (\%) (of 88 Samples) \\
\hline I DRG & $69 / 88(78.4)$ \\
2 DRGs & $19 / 88(21.6)$ \\
I DR & $69 / 88(78.4)$ \\
2 DRs & $19 / 88(21.6)$ \\
I VR & $3 / 88(3.4)$ \\
2 VRs & $85 / 88(96.6)$ \\
\hline
\end{tabular}

Abbreviations: DRG, dorsal root ganglia; DR, dorsal root; VR, ventral root. 
Table 2 Percentage of Singular DRG, Biganglia and Triganglia Seen at Lumbar Dorsal Root ${ }^{19,20}$

\begin{tabular}{|l|l|l|l|}
\hline Dorsal Root & Singular DRG & Biganglia & Triganglia \\
\hline LI & $95.2 \%$ & $4.8 \%$ & $0.0 \%$ \\
L2 & $72.6 \%$ & $26.1 \%$ & $1.3 \%$ \\
L3 & $55.2 \%$ & $43.9 \%$ & $0.9 \%$ \\
L4 & $41.3 \%$ & $58.0 \%$ & $0.8 \%$ \\
L5 & $71.5 \%$ & $27 \%$ & $1.5 \%$ \\
\hline
\end{tabular}

intraspinal, foraminal, or extraforaminal - were also found to vary significantly at each spinal segment (Figures 2 and 3). ${ }^{19-21,23,25-31}$ This variable location within the DREZC results in a relative change in the adjacent DR and DRL segments (Figure 1). Furthermore, the number of DRLs was found to range from 2 to 15 , depending on spinal level, ${ }^{2,5,21,24,32-35}$ and the location and size of the DREZ itself, compared to midline and the posterolateral sulcus, was also found to be variable. , $^{2,24,32,34}$

Secondly, and perhaps most importantly, the intraprocedural imaging technology typically utilized to target individual components of the DREZC during radiofrequency procedures is fluoroscopy. Fluoroscopy is limited in its capacity to identify individual components of the DREZC (Figure 4). ${ }^{8,12,36}$ Fluoroscopy utilizes tubular x-ray technology, a 2-dimensional modality that cannot directly visualize nervous tissue at any component of the DREZC, but does allow for visualization of boney architecture, which allows the physician to approximate the position of the radiofrequency cannula tip to the target lesion. ${ }^{8}$ This approximation does not guarantee accurate placement of the cannula tip adjacent to any one component of the DREZC.

\section{Clinical Correlation}

Hence, when this anatomic diversity is taken into account in the context of the limited capacity of the most commonly utilized intra-procedural imaging technology (fluoroscopy) to identify individual segments of the DREZC, the logical presumption might be that radiofrequency lesions of the DREZC may be fraught with high failure rates, and that the more invasive classic surgical DREZ lesion may provide better outcomes. Conversely, however, outcomes for both non-surgical ablative ${ }^{37}$ and non-surgical neuromodulatory ${ }^{9}$ radiofrequency lesions are generally favorable (Figure 5), while the more invasive surgical approach was fraught with complications (Table 3 ) and a comparable degree of analgesia (Figure 6). Moreover, an analysis of cannula tip placement in relation to the pedicle and foramen showed that neuromodulatory pulsed radiofrequency outcomes were similarly successful in treating lumbar radicular pain irrespective of cannula position (intraspinal, deep to the pedicle, versus extraforaminal, outside of pedicle), even though this modality (x-rays) cannot accurately localize the cannula tip to any one targeted component of the DREZC. ${ }^{38}$

The more invasive classic surgical DREZotomy procedure utilizes microsurgical dissection to visualize the target lesions, then utilizes similar radiofrequency ablative cannulas to induce finite lesions through a $1-2 \mathrm{~mm}$ active tip. ${ }^{15,17,39,40}$ Despite the careful planning and surgical

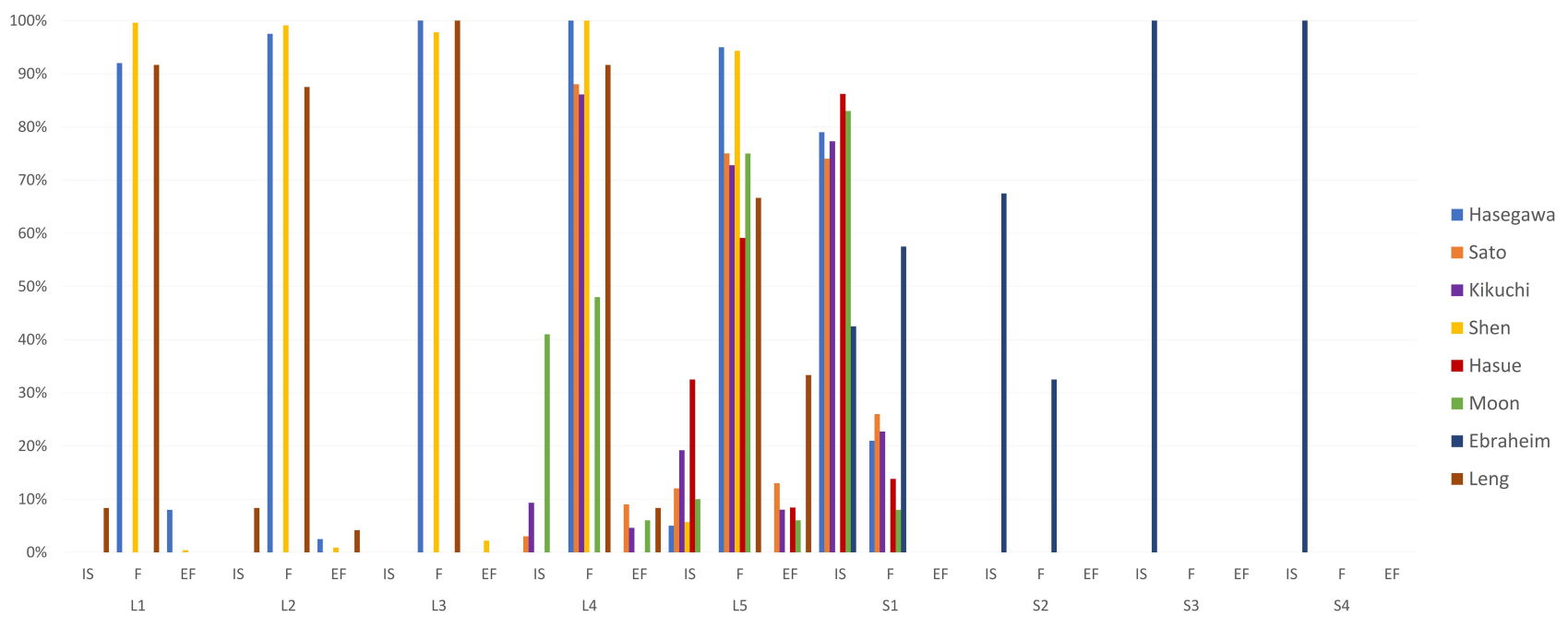

Figure 2 DRG-foraminal anatomy from $\mathrm{LI}$ through $\mathrm{S} 4$ spinal levels. Abbreviations: IS, intraspinal; F, foraminal; EF, extraforaminal. 


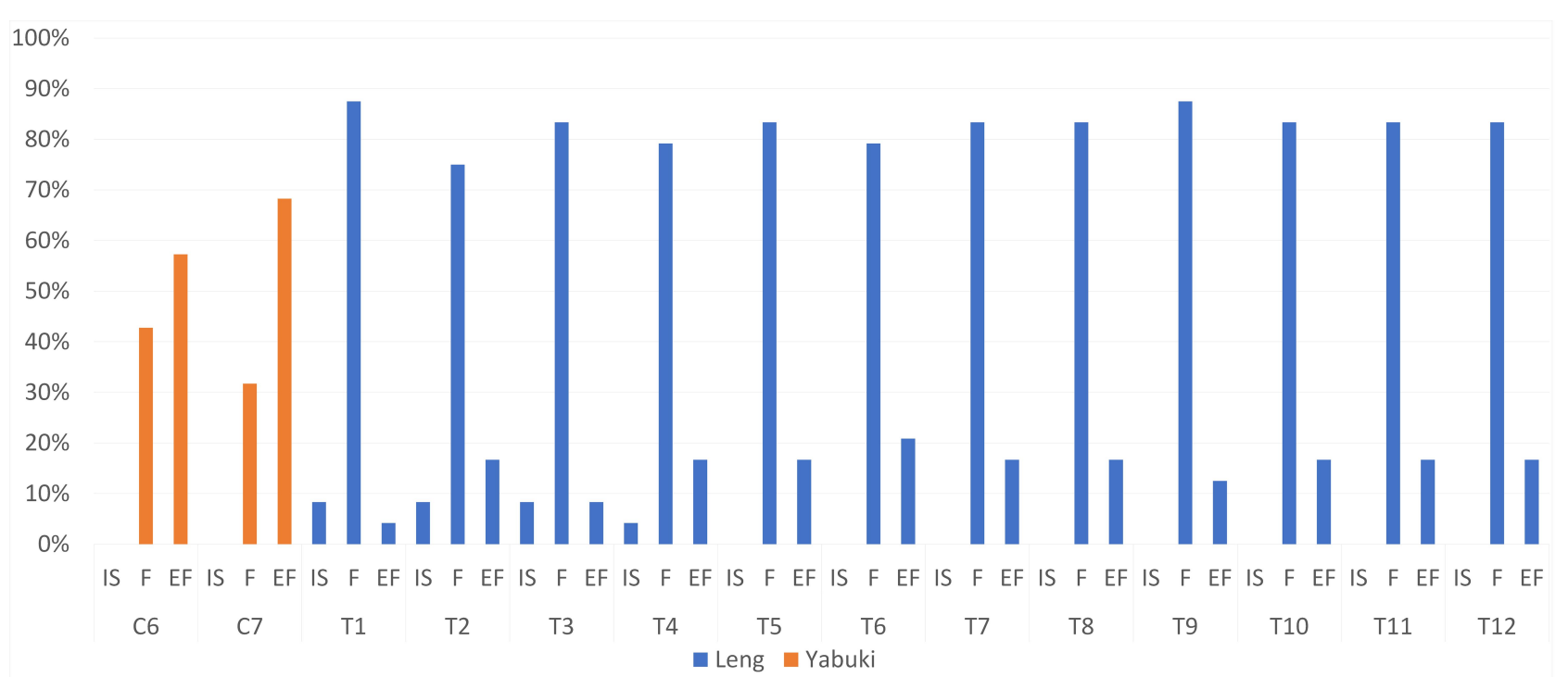

Figure 3 DRG-foraminal anatomy from C6 through TI2 spinal levels.

Note: C8 DRG anatomy not described in source data.

Abbreviations: IS, intraspinal; F, foraminal; EF, extraforaminal.

dissection for direct visualization and localization, most studies report significant failure rate to achieve adequate analgesia (Figure 6), with numerous complications (Table $3)$. One explanation for these surgical failure rates may be due to the lack of intra-operative nerve stimulation for

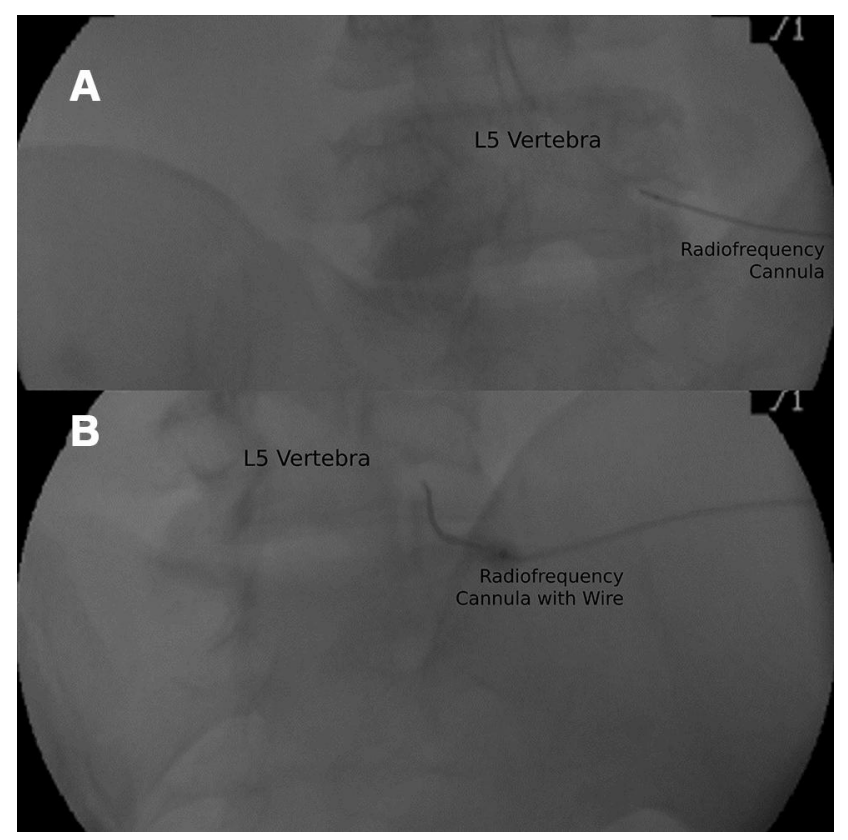

Figure 4 Fluoroscopic image of a radiofrequency needle placement and wire insertion for neurosensory stimulation prior to neuromodulatory pulsed radiofrequency right L5 DREZC lesion. (A) Posteroanterior fluoroscopic view. (B) Right oblique fluoroscopic view $-25^{\circ}$. Deidentified mage obtained from Dr. Visnjevac with documented patient consent. localization in all cases. Intra-operative nerve stimulation has shown that stimulation of the DREZ fails to evoke a response in some patients, emphasizing that dorsolateral stimulation resulted in larger amplitude spinal cord evoked potentials than did dorsal stimulation. ${ }^{41,42}$ Tomas et al showed that intraoperative stimulation resulted in significantly better pain relief than when no nerve stimulation was used (odds ratio $=10$ ). ${ }^{43}$ Others have also showed improved outcomes when neurostimulation is utilized intraoperatively. ${ }^{44}$

Similar neurosensory stimulation is used intraprocedurally for fluoroscopically guided radiofrequency lesions of the DREZC (Figure 4), to localize the dorsal sensory pathways, prior to treatment with application of either pulsed or continuous radiofrequency energy to the DREZC. ${ }^{9,14,45-52}$ A similar process is utilized during surgical implantation of DRG stimulators. ${ }^{53}$ Irrespective of the procedure being performed, this neurosensory stimulation is a process non-specific to any one component of the DREZC, as any component within this linear sensory pathway will transmit a similar positive sensory response as any adjacent segment of the DREZC. ${ }^{11}$ This positive correlation between sensory capture and positive clinical outcomes is a direct reflection of sensory capture of the DREZC, rather than capture of any one component alone.

It is also important to note that there are differences in safety favoring the fluoroscopically guided minimally invasive DREZC lesion approach. Compared to the 


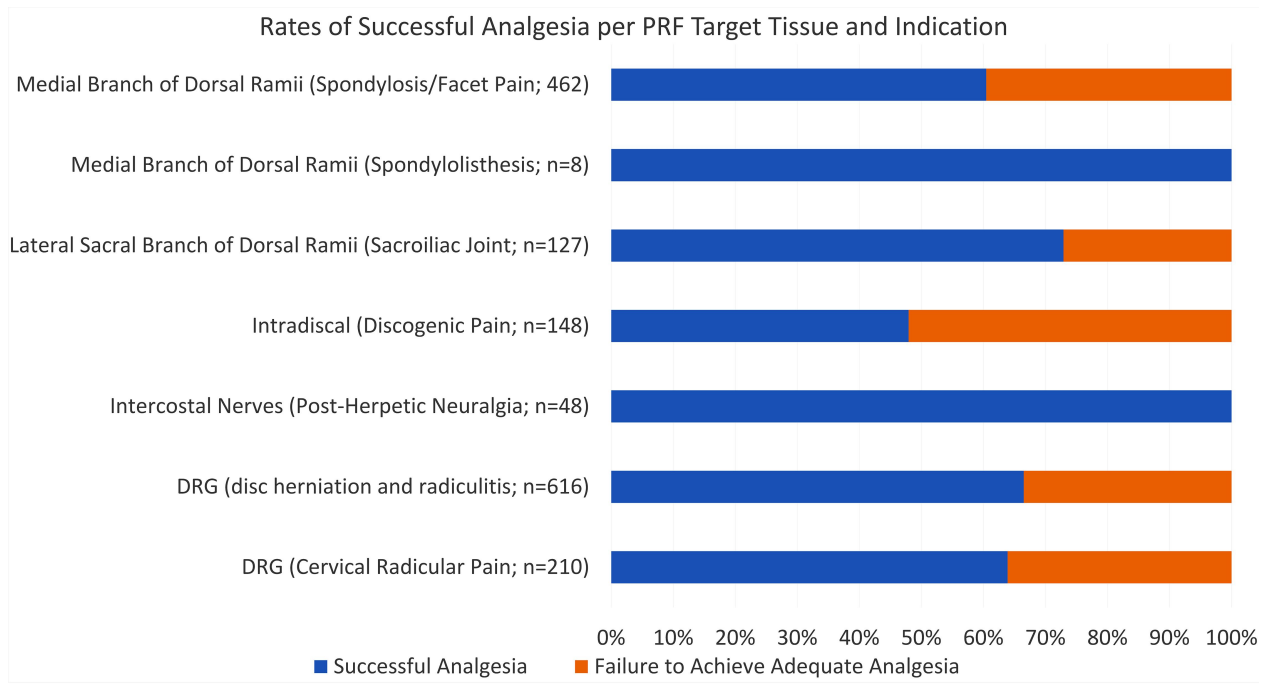

Figure 5 Pulsed radiofrequency DREZC lesion success and failure rates to achieve adequate analgesia per indication. Extrapolated from, Facchini G, Spinnato P, Guglielmi G, Albisinni U, Bazzocchi A. A comprehensive review of pulsed radiofrequency in the treatment of pain associated with different spinal conditions. Br J Radiol 20I7; 90 : $20,150,406 .^{9}$

surgically induced structural lesions using higher temperature continuous radiofrequency thermocoagulation of the DREZ, itself, pulsed radiofrequency of the DREZC has been utilized as a non-ablative, neuromodulatory method, of treating neuropathic pain ${ }^{9,54-57}$ with comparable success rates (Figure 5$)^{9,38,58}$ to surgical DREZ lesions (Figure 6).

\section{Discussion}

The purpose of this translational review was to provide evidence in the support of the natural evolution of the nomenclature of radiofrequency lesions from lesions of individualized components of the dorsal afferent pathway to, henceforth, refer to these neuroablative and/or neuromodulatory radiofrequency lesions of this linear pathway as, "Dorsal Root Entry Zone Complex (DREZC) lesions." Although current nomenclature is presumptively precise to each individual lesion, the clinical imaging tools commonly utilized in clinical practice do not allow for it to be as accurate as the new "DREZC lesions" nomenclature. This nomenclature transition is supported by the following evidence as outlined herein:

(a) There is a high degree of anatomic variability of the dorsal root ganglia, varying in number from 1 to 3 per spinal level (Tables 1 and 2), and in their locations relative to their respective foramina (Figures 2 and 3).

(b) The number of DRLs was found to range from 2 to 15 , depending on spinal level,,$^{2,5,21,24,32-35}$ and the location and size of the DREZ itself, compared to midline and the posterolateral sulcus, was also found to be variable. $^{2,5,24,32,34}$

(c) The use of fluoroscopy does not and cannot identify individual components of the DREZC (Figures 1 and 4). ${ }^{8,11}$

(d) The radiofrequency cannula tip position compared to the DRG did not impact the efficacy of pulsed radiofrequency lesions of the DREZC. ${ }^{38}$

(e) There is evidence that the more procedurally accessible dorsolateral, rather than dorsal columns, intraoperative nerve stimulation yield better outcomes ${ }^{2,41-43}$ (note: the dorsolateral cord communicates with the DRLs and the more distal portions of the DREZC ${ }^{5}$ ).

Intraoperatively, both surgical exposure with direct visualization and the use of fluoroscopy have their limitations with resultant failure rates (Figures 5 and 6, Table 3). When neurosensory mapping is used to supplement surgical exposure of fluoroscopic imaging to identify the dorsal segments correlating with the patient's pain, the technology utilized for neurosensory mapping does not itself differentiate between the individual DREZC components, and yet efficacy is not compromised, ${ }^{38,43,44,53}$ further supporting the assertion for the nomenclature to rightfully evolve to the more sensitive and inclusive terminology, "DREZC lesions."

This improved accuracy in nomenclature will, inherently, be limited by a loss of precision as each component of the DREZC would no longer be presumptively labelled. Such a nomenclature change does not, however, prevent more specific anatomic or clinical 
Table 3 Transient and Serious or Long-Term Complications Following DREZ Surgical Lesions

\begin{tabular}{|c|c|c|}
\hline \multicolumn{3}{|c|}{ Post-Operative Complications Following Surgical DREZ Lesioning } \\
\hline Author (Date) & Transient Complications & Severe or Lasting Complications \\
\hline \multirow[t]{3}{*}{ Bing $(2019)^{60}$} & $\begin{array}{l}10 \text { of } 42: \text { diffuse pruritis (average } 3 \text { days), } \\
\text { symptoms alleviated through low-dose } \\
\text { intramuscular injection }\end{array}$ & $\begin{array}{l}3 \text { of 42: permanent tingling pain affecting daily life, } 2 \text { of which had } \\
\text { resolution with adjacent level DREZ lesions; I remanded to oral } \\
\text { analgesics }\end{array}$ \\
\hline & 2 of $42:$ wound dehiscence & $\begin{array}{l}\text { I of 42: recurrence of pain in the original pain area that increasingly } \\
\text { worsened }\end{array}$ \\
\hline & I of 42 : urinary tract infection & \\
\hline \multirow[t]{2}{*}{ Takai $(2017)^{61}$} & I of I0: sensory deficit, resolved within I month & \multirow[t]{2}{*}{ I of I0: a new persistent pain requiring oral analgesics } \\
\hline & 2 of 10: new adjacent level pain for $<1$ month & \\
\hline \multirow[t]{3}{*}{ Chivukula $(2015)^{10}$} & I of 83: atelectasis & 3 of 83: paresis \\
\hline & 2 of 83: post-op colitis & 3 of $83:$ neuropathy/radiculopathy \\
\hline & & 2 of 83: persistent incisional site pain \\
\hline Ko $(2016)^{62}$ & None reported & None reported \\
\hline Awad $(2013)^{63}$ & None reported & 2 of 19: motor weakness \\
\hline \multirow[t]{2}{*}{ Ruiz-Juretschke $(201 \mathrm{I})^{16}$} & $\begin{array}{l}3 \text { of 18: transient proprioceptive sensory } \\
\text { disturbance }\end{array}$ & $\begin{array}{l}\text { I of I8: death } 9 \text { days post-operatively following nosocomial } \\
\text { pneumonia }\end{array}$ \\
\hline & 2 of I8: CSF leak & $\begin{array}{l}\text { I of I8: dorsal post-surgical myelopathy treated with bilateral low } \\
\text { dorsal DREZ surgical lesions }\end{array}$ \\
\hline \multirow[t]{4}{*}{ Zhang $(2008)^{64}$} & \multirow{4}{*}{$\begin{array}{l}\text { I3 of } 23 \text { : transient hyperalgesia in the upper } \\
\text { chest, secondary to prolonged operative } \\
\text { positioning }\end{array}$} & 8 of 23: transient slight hemiplegia \\
\hline & & 15 of $23:$ hypesthesia and paresthesia \\
\hline & & 6 of 23: a bearing down feeling of affected extremity \\
\hline & & 4 of 23: deep sensory disability in the lower limbs \\
\hline \multirow[t]{2}{*}{ Tomas $(2005)^{43}$} & \multirow[t]{2}{*}{ None reported } & 2 of 21 : sustained motor deficits \\
\hline & & I of 2 I: sustained sensory deficits \\
\hline \multirow[t]{3}{*}{ Sindou $(200 \mathrm{I})^{65}$} & 3 of 44: CSF leak & \multirow[t]{3}{*}{ I of 44: bacteremia } \\
\hline & 2 of $44:$ wound infection & \\
\hline & I of 44 : subcutaneous hematoma & \\
\hline \multirow[t]{2}{*}{ Samii $(200 I)^{66}$} & \multirow[t]{2}{*}{ None reported } & 2 of 47 : subdural hematoma \\
\hline & & 7 of 47 : motor weakness \\
\hline \multirow[t]{6}{*}{ Edgar $(1993)^{40}$} & 3 of II2: CSF leak & 2 of II2: sensory deficits \\
\hline & 5 of I12: myelopathic myoclonus & 3 of I12: motor deficits \\
\hline & & I of I|2: spine instability \\
\hline & & 2 of II2: pulmonary embolus \\
\hline & & 8 of 112 : treatment failure (no analgesia) \\
\hline & & 2 of II2: suicide $1-2$ years post operatively \\
\hline
\end{tabular}


Table 3 (Continued).

\begin{tabular}{|c|c|c|}
\hline \multicolumn{3}{|c|}{ Post-Operative Complications Following Surgical DREZ Lesioning } \\
\hline Author (Date) & Transient Complications & Severe or Lasting Complications \\
\hline \multirow[t]{4}{*}{ Kumagai $(1992)^{67}$} & \multirow[t]{4}{*}{ None reported } & 12 of 15: Sensory loss \\
\hline & & 7 of 15: motor weakness \\
\hline & & 4 of 15: paraesthesia \\
\hline & & 6 of 15: a new pain \\
\hline \multirow[t]{5}{*}{ Young $(1990)^{68}$} & \multirow[t]{5}{*}{ None reported } & $\begin{array}{l}\text { I of } 78 \text { patients: reduced sensation, paraparesis, and altered } \\
\text { sphincter function. }\end{array}$ \\
\hline & & I of 78 patients: bowel and bladder incontinence \\
\hline & & I of 78 patients: near complete paraplegia \\
\hline & & 7 of 78 ipsilateral leg weakness \\
\hline & & 7 of 78 : loss of proprioception \\
\hline Campbell $(1988)^{69}$ & 2 of 10 patients: hyperreflexia & None reported \\
\hline Garcia-March $(1987)^{70}$ & I of II patients: transient weakness & None reported \\
\hline \multirow[t]{2}{*}{ Thomas $(1984)^{71}$} & 7 of 19: motor weakness & I of 19: severe motor weakness \\
\hline & 5 of 19: sensory deficits (mostly proprioception) & Some patients had persistent sensory deficits (details unclear) \\
\hline \multirow[t]{3}{*}{ Samii $(1984)^{66}$} & 9 of 35: sensory deficits & \multirow[t]{3}{*}{ None } \\
\hline & I of 35: motor deficits & \\
\hline & 8 of $35:$ motor and sensory deficits & \\
\hline \multirow[t]{4}{*}{ Richter $(1984)^{72}$} & \multirow[t]{4}{*}{ I of 10: transient weakness } & 2 of 10: died post-operatively \\
\hline & & I of I0: Brown-Sequard type hypoesthesia \\
\hline & & 2 of 10: Unilateral hypoesthesia \\
\hline & & I of I0: motor and sensory deficits \\
\hline
\end{tabular}

investigation, if future imaging advancements provide for more accurate localization of individual DREZC components, of if new lesioning techniques are developed.

Furthermore, the classic segmental nomenclature, in its current form, does not allow for effective research and comparison of the milieu of procedures noted above, all of which refer to RF lesions of the same linear sensory pathway. Irrespective of advances in the accuracy of imaging technologies, which may be able to identify individual component of the DREZC, this proposed nomenclature change would allow for direct comparison of clinical outcomes for lesions along the same DREZC sensory pathway using technology actively utilized in clinical practice today.
Contributing to these similar outcomes, one must consider an important procedural difference between classic surgical DREZ lesions and fluoroscopically guided DREZC lesions. While small radiofrequency electrodes with 1-2 $\mathrm{mm}$ active tips are utilized for ablative radiofrequency DREZ surgeries in an effort to minimize the complications (Table 3), larger active tips (ie, $10 \mathrm{~mm}$ ) can safely be used for pulsed radiofrequency procedures as the temperatures are typically maintained at $42^{\circ} \mathrm{C}$, which have not been found to be ablative, ${ }^{38,54,55,59}$ but rather, neuromodulatory. ${ }^{9,45,59}$ The larger active tip may provide enough linear anatomic capture to induce broad neuromodulatory changes, potentially modulating multiple components of the dorsal sensory pathway - an important consideration considering the anatomic variability of 
Spinal Cord Injury (Young 1990)

Spinal Cord Injury (Samii 1984)

Spinal Cord Injury (Richter 1984)

Spinal Cord Injury (Bing 2019)

Segmental Pain (Sindou 2001)

Root Avulsion Injury (Takai 2017)

Post-Herpetic Neuralgia (Young 1990)

Post-Amputation Phantom Pain (Young 1990)

Post-Amputation Phantom Pain (Samii 1984)

Peripheral Nerve Lesion (Samii 1984)

Paroxysmal Pain (Sindou 2001)

Multiple Sclerosis (Samii 1984)

Lumbosacral Plexus Injury (Young 1990)

Intercostal Neuralgia (Samii 1984)

Infralesional Pain (Sindou 2001)

Deafferentation Pain (Zhang 2008)

Deafferentation Pain (Ruiz-Juretschke 2011)

Continuous Pain (Sindou 2001)

Cauda Equina Injury (Young 1990)

Breast Cancer (Samii 1984)

Brachial Plexus Injury (Young 1990)

Brachial Plexus Avulsion (Tomas 2005)

Brachial Plexus Avulsion (Thomas 1984)

Brachial Plexus Avulsion (Samii 1984)

Brachial Plexus Avulsion (Ko 2016)

Successful Analgesia
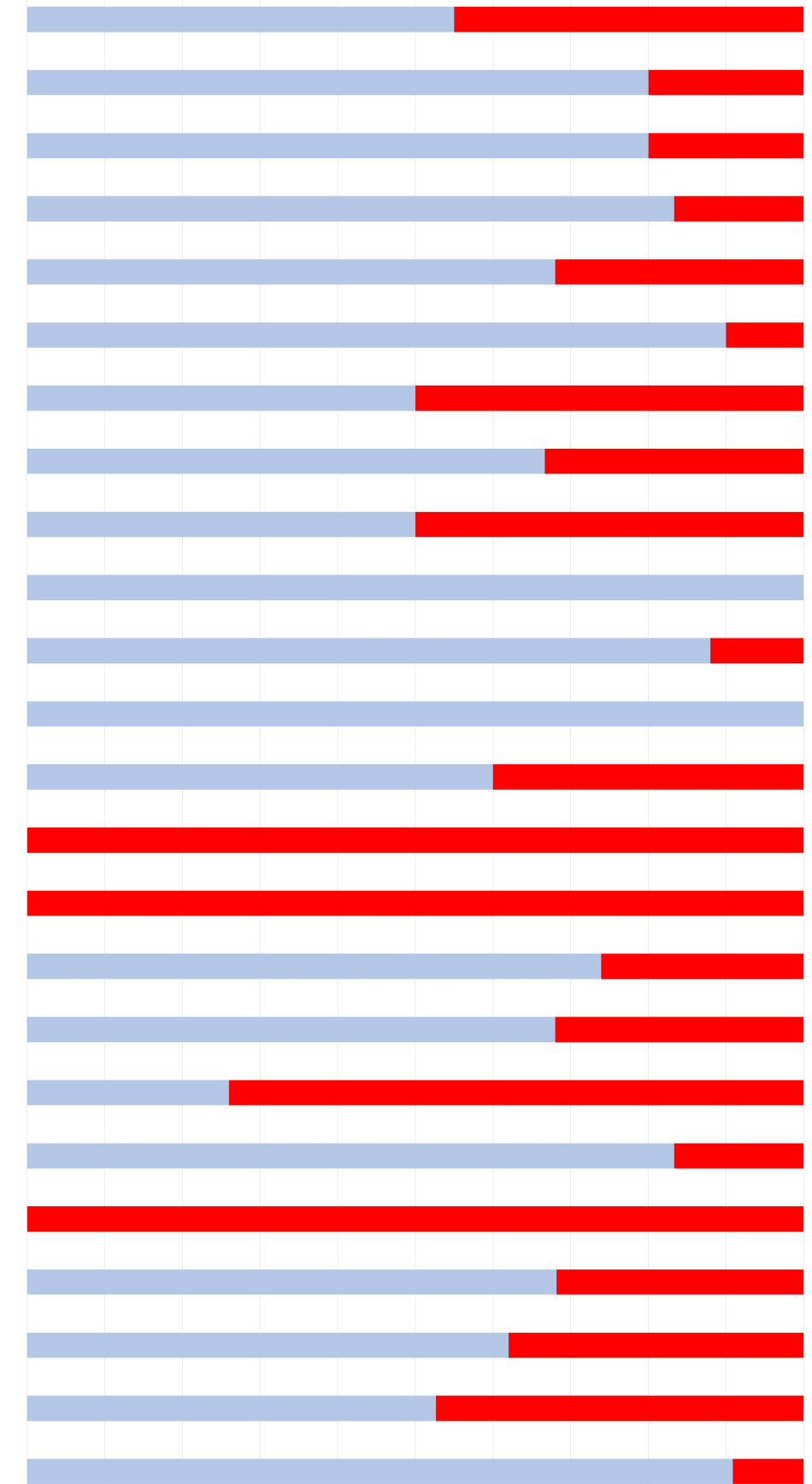

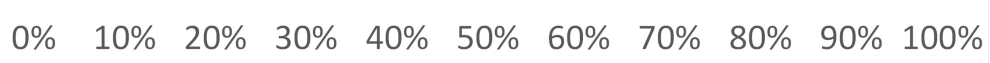

- Failure to Achieve Adequate Analgesia

Figure 6 Surgical DREZ RF lesion success and failure rates to achieve adequate analgesia per indication.

DRGs and DRs (Tables 1 and 2), the variability of their locations relative to their respective foramina and DRLs (Figures 2 and 4), and variability in number, size, and location of both DRLs ${ }^{2,5,21,24,32-35}$ and the DREZ, varied along the linear dorsal afferent pathway, indicating itself. ${ }^{2,5,24,32,34}$ Even with the anatomical variability of the DRG in relation to the foramen, the efficacy of pulsed radiofrequency lesions was maintained while cannula placement 
that the cannula tip does not significantly impact efficacy when DREZC neurosensory stimulatory capture is attained. ${ }^{38}$ Although this may partially be explained due to the larger pulsed radiofrequency active tip capturing a larger anatomic portion of the DREZC, given the anatomic variability of the DRGs, DRs, DRLs, and DREZ, it appears that the neuromodulatory effects can materialize with a pulsed radiofrequency lesion at variable segments of the DREZC.

Thus, the use of the term, "DREZC lesion," avoids the presumptive incorrect classic segmental nomenclature. If, for example, an T12 fluoroscopically-confirmed intraspinal cannula tip results in appropriate sensory stimulation in a patient who had 2 DRGs, each located extraforaminally, it would be incorrect to label such a procedure as pulsed radiofrequency of the DRG since this would be a lesion of the DRL or DREZ, as evidenced by an intraspinal cannula tip, more proximal to the extraforaminal DRGs. In this scenario, the DRG could not itself be visualized using fluoroscopy thereby limiting the accuracy of the current nomenclature. "DREZC lesion," on the other hand, would be accurate in same scenario.

\section{Conclusion}

The purpose of this translational review was to provide evidence in the support of the natural evolution of the nomenclature of radiofrequency lesions from lesions of individualized components of the dorsal afferent pathway to, henceforth, refer to these neuroablative and/or neuromodulatory radiofrequency lesions of this linear pathway as, "Dorsal Root Entry Zone Complex (DREZC) lesions." Review of anatomic variability, procedural limitations and complications, along with patient outcomes, all support the change to this more sensitive and inclusive terminology nomenclature. Clinically, and academically, this would be a more accurate nomenclature, whereby technological limitations for intraprocedural identification and differentiation of any one component of the DREZC to another adjacent component could be considered less clinically relevant with the new, more encompassing, nomenclature, given that clinical data show similar outcomes despite these limitations. This review demonstrates that technological limitations for intraprocedural identification and differentiation of any one component of the DREZC to another component could be considered to have limited clinical relevance since lesions of individual components of this linear dorsal sensory pathway (DREZC) have yielded similar clinical outcomes by interrupting signal transmission through the same pathway. Furthermore, to arbitrarily name presumptive individual component lesions of the DREZC inaccurately would be inappropriate. Clinically, and academically, "DREZC Lesions," would provide a more inclusive and accurate nomenclature for collective RF lesions of the DREZC components, which can provide a cohesive direction for reporting neuroablative outcomes for DREZC lesions. Future imaging advancements may improve clinical accuracy, at which point the nomenclature may be reassessed yet again, but given today's limitation, the evidence supports the use of the more sensitive and accurate nomenclature, DREZC lesions.

\section{Acknowledgment}

We would like to thank Viola Visnjevac for her artistic contribution to Figure 1.

\section{Disclosure}

Alaa Abd-Elsayed reports serving as a consultant for Medtronic and Avanos. The authors report no other potential conflicts of interest in this body of work.

\section{References}

1. Pizzo P. Relieving Pain in America: A Blueprint for Transforming Prevention, Care, Education, and Research. Washington (DC); 2011.

2. Kirazli O, Tatarli N, Guclu B, et al. Anatomy of the spinal dorsal root entry zone: its clinical significance. Acta Neurochir (Wien). 2014;156 (12):2351-2358. doi:10.1007/s00701-014-2252-0

3. Purves D, Augustine GJ, Fitzpatrick D. The internal anatomy of the spinal cord. In: Purves DAG, Fitzpatrick D, editors. Neuroscience. Sunderland (MA): Sinauer Associates; 2001.

4. Anatomy and physiology of the spinal cord; 2000-2013. Available from: https://www.ncbi.nlm.nih.gov/books/NBK6229/. Accessed December 7, 2020.

5. Karatas A, Caglar S, Savas A, Elhan A, Erdogan A. Microsurgical anatomy of the dorsal cervical rootlets and dorsal root entry zones. Acta Neurochir (Wien). 2005;147(2):195-199.

6. Konrad P. Dorsal root entry zone lesion, midline myelotomy and anterolateral cordotomy. Neurosurg Clin N Am. 2014;25 (4):699-722. doi:10.1016/j.nec.2014.07.010

7. Bogduk N, Wilson AS, Tynan W. The human lumbar dorsal rami. J Anat. 1982;134(Pt2):383-397.

8. Bogduk N, Long DM. Percutaneous lumbar medial branch neurotomy: a modification of facet denervation. Spine (Phila Pa 1976). 1980;5(2):193-200. doi:10.1097/00007632-198003000-00015

9. Facchini G, Spinnato P, Guglielmi G, Albisinni U, Bazzocchi A. A comprehensive review of pulsed radiofrequency in the treatment of pain associated with different spinal conditions. $\mathrm{Br} J$ Radiol. 2017;90(1073):20150406. doi:10.1259/bjr.20150406

10. Chivukula S, Tempel ZJ, Chen CJ, Shin SS, Gande AV, Moossy JJ. Spinal and nucleus caudalis dorsal root entry zone lesioning for chronic pain: efficacy and outcomes. World Neurosurg. 2015;84 (2):494-504. doi:10.1016/j.wneu.2015.04.025

11. Soloman M, Mekhail MN, Mekhail N. Radiofrequency treatment in chronic pain. Expert Rev Neurother. 2010;10(3):469-474. doi:10.15 86/ern.09.153

12. Kapural L, Nageeb F, Kapural M, Cata JP, Narouze S, Mekhail N. Cooled radiofrequency system for the treatment of chronic pain from sacroiliitis: the first case-series. Pain Pract. 2008;8(5):348-354. doi:10.1111/j.1533-2500.2008.00231.x 
13. Cohen SP, Doshi TL, Constantinescu OC, et al. Effectiveness of lumbar facet joint blocks and predictive value before radiofrequency denervation: the facet treatment study (facts), a randomized, controlled clinical trial. Anesthesiology. 2018;129(3):517-535. doi:10.10 97/ALN.0000000000002274

14. Abejon D, Garcia-del-Valle S, Fuentes ML, Gomez-Arnau JI, Reig E, van Zundert J. Pulsed radiofrequency in lumbar radicular pain: clinical effects in various etiological groups. Pain Pract. 2007;7 (1):21-26. doi:10.1111/j.1533-2500.2007.00105.x

15. Rawlings CE 3rd, El-naggar AO, Nashold BS. The DREZ procedure: an update on technique. $B r J$ Neurosurg. 1989;3(6):633-642. doi: $10.3109 / 02688698908992686$

16. Ruiz-Juretschke F, Garcia-Salazar F, Garcia-Leal R, et al. Treatment of neuropathic deafferentation pain using DREZ lesions; long-term results. Neurologia. 2011;26(1):26-31. doi:10.1016/j.nrl.2010.10.003

17. Monaco BA, Lopes AJM, Teixeira MJ. Ultrasound-guided DREZotomy: technical note. Stereotact Funct Neurosurg. 2019;97 (2):127-131. doi:10.1159/000500491

18. Choi EJ, Choi YM, Jang EJ, Kim JY, Kim TK, Kim KH. Neural ablation and regeneration in pain practice. Korean J Pain. 2016;29 (1):3-11. doi:10.3344/kjp.2016.29.1.3

19. Kikuchi S, Sato K, Konno S, Hasue M. Anatomic and radiographic study of dorsal root ganglia. Spine (Phila Pa 1976). 1994;19(1):6-11. doi:10.1097/00007632-199401000-00002

20. Shen J, Wang HY, Chen JY, Liang BL. Morphologic analysis of normal human lumbar dorsal root ganglion by 3D MR imaging. AJNR Am J Neuroradiol. 2006;27(10):2098-2103.

21. Leng L, Liu L, Si D. Morphological anatomy of thoracolumbar nerve roots and dorsal root ganglia. Eur J Orthop Surg Traumatol. 2018;28 (2):171-176. doi:10.1007/s00590-017-2026-5

22. Haberberger RV, Barry C, Dominguez N, Matusica D. Human dorsal root ganglia. Front Cell Neurosci. 2019;13:271. doi:10.3389/fncel.2019.00271

23. Cohen MS, Wall EJ, Brown RA, Rydevik B, Garfin SR. 1990 AcroMed award in basic science. Cauda equina anatomy. II: extrathecal nerve roots and dorsal root ganglia. Spine (Phila Pa 1976). 1990;15(12):1248-1251. doi:10.1097/00007632-199012000-00003

24. Alleyne CH Jr, Cawley CM, Barrow DL, Bonner GD. Microsurgical anatomy of the dorsal cervical nerve roots and the cervical dorsal root ganglion/ventral root complexes. Surg Neurol. 1998;50(3):213-218. doi:10.1016/S0090-3019(97)00315-7

25. Hasegawa T, Mikawa Y, Watanabe R, An HS. Morphometric analysis of the lumbosacral nerve roots and dorsal root ganglia by magnetic resonance imaging. Spine (Phila Pa 1976). 1996;21(9):1005-1009. doi:10.1097/00007632-199605010-00001

26. Sato K, Kikuchi S. An anatomic study of foraminal nerve root lesions in the lumbar spine. Spine (Phila Pa 1976). 1993;18(15):2246-2251. doi:10.1097/00007632-199311000-00017

27. Moon HS, Kim YD, Song BH, Cha YD, Song JH, Lee MH. Position of dorsal root ganglia in the lumbosacral region in patients with radiculopathy. Korean J Anesthesiol. 2010;59(6):398-402. doi:10.40 97/kjae.2010.59.6.398

28. Hasue M, Kunogi J, Konno S, Kikuchi S. Classification by position of dorsal root ganglia in the lumbosacral region. Spine (Phila Pa 1976). 1989;14(11):1261-1264. doi:10.1097/00007632-198911000-00021

29. Ebraheim NA, Lu J. Morphometric evaluation of the sacral dorsal root ganglia. A cadaveric study. Surg Radiol Anat. 1998;20(2):105-108.

30. Silav G, Arslan M, Comert A, et al. Relationship of dorsal root ganglion to intervertebral foramen in lumbar region: an anatomical study and review of literature. $J$ Neurosurg Sci. 2016;60 (3):339-344

31. Silverstein MP, Romrell LJ, Benzel EC, Thompson N, Griffith S, Lieberman IH. Lumbar dorsal root Ganglia location: an anatomic and MRI assessment. Int J Spine Surg. 2015;9:3. doi:10.14444/2003

32. Bozkurt M, Canbay S, Neves GF, et al. Microsurgical anatomy of the dorsal thoracic rootlets and dorsal root entry zones. Acta Neurochir (Wien). 2012;154(7):1235-1239. doi:10.1007/s00701-012-1395-0
33. Hauck EF, Wittkowski W, Bothe HW. Intradural microanatomy of the nerve roots S1-S5 at their origin from the conus medullaris. J Neurosurg Spine. 2008;9(2):207-212. doi:10.3171/SPI/2008/9/8/207

34. Xiang JP, Liu XL, Xu YB, Wang JY, Hu J. Microsurgical anatomy of dorsal root entry zone of brachial plexus. Microsurgery. 2008;28 (1):17-20. doi:10.1002/micr.20438

35. Zhou MW, Wang WT, Huang HS, Zhu GY, Chen YP, Zhou CM. Microsurgical anatomy of lumbosacral nerve rootlets for highly selective rhizotomy in chronic spinal cord injury. Anat Rec (Hoboken). 2010;293(12):2123-2128. doi:10.1002/ar.21213

36. Bogduk N, Macintosh J, Marsland A. Technical limitations to the efficacy of radiofrequency neurotomy for spinal pain. Neurosurgery. 1987;20(4):529-535. doi:10.1227/00006123-198704000-00004

37. Leggett LE, Soril LJ, Lorenzetti DL, et al. Radiofrequency ablation for chronic low back pain: a systematic review of randomized controlled trials. Pain Res Manag. 2014;19(5):e146-153. doi:10.1155/2014/834369

38. Kim WJ, Park HS, Park MK. The effect of needle tip position on the analgesic efficacy of pulsed radiofrequency treatment in patients with chronic lumbar radicular pain: a retrospective observational study. Korean J Pain. 2019;32(4):280-285. doi:10.3344/ kjp.2019.32.4.280

39. Nashold BS Jr. Neurosurgical technique of the dorsal root entry zone operation. Appl Neurophysiol. 1988;51(2-5):136-145.

40. Edgar RE, Best LG, Quail PA, Obert AD. Computer-assisted DREZ microcoagulation: posttraumatic spinal deafferentation pain. $J$ Spinal Disord. 1993;6(1):48-56. doi:10.1097/00002517-199302000-00009

41. Fazl M, Houlden DA, Kiss Z. Spinal cord mapping with evoked responses for accurate localization of the dorsal root entry zone. $J$ Neurosurg. 1995;82(4):587-591. doi:10.3171/jns.1995.82.4.0587

42. Fazl M, Houlden DA. Dorsal root entry zone localization using direct spinal cord stimulation: an experimental study. J Neurosurg. 1995;82 (4):592-594. doi:10.3171/jns.1995.82.4.0592

43. Tomas R, Haninec P. Dorsal root entry zone (DREZ) localization using direct spinal cord stimulation can improve results of the DREZ thermocoagulation procedure for intractable pain relief. Pain. 2005;116(1-2):159-163. doi:10.1016/j.pain.2005.03.015

44. Falci S, Best L, Bayles R, Lammertse D, Starnes C. Dorsal root entry zone microcoagulation for spinal cord injury-related central pain: operative intramedullary electrophysiological guidance and clinical outcome. J Neurosurg. 2002;97(2Suppl):193-200.

45. Chua NH, Vissers KC, Sluijter ME. Pulsed radiofrequency treatment in interventional pain management: mechanisms and potential indications-a review. Acta Neurochir (Wien). 2011;153(4):763-771. doi:10.1007/s00701-010-0881-5

46. Van Zundert J, Patijn J, Kessels A, Lame I, van Suijlekom H, van Kleef M. Pulsed radiofrequency adjacent to the cervical dorsal root ganglion in chronic cervical radicular pain: a double blind sham controlled randomized clinical trial. Pain. 2007;127(1-2):173-182. doi:10.1016/j.pain.2006.09.002

47. Chang MC, Cho YW, Ahn SH. Comparison between bipolar pulsed radiofrequency and monopolar pulsed radiofrequency in chronic lumbosacral radicular pain: a randomized controlled trial. Medicine (Baltimore). 2017;96(9):e6236. doi:10.1097/MD.0000000 000006236

48. Choi GS, Ahn SH, Cho YW, Lee DG. Long-term effect of pulsed radiofrequency on chronic cervical radicular pain refractory to repeated transforaminal epidural steroid injections. Pain Med. 2012;13(3):368-375. doi:10.1111/j.1526-4637.2011.01313.x

49. Choi GS, Ahn SH, Cho YW, Lee DK. Short-term effects of pulsed radiofrequency on chronic refractory cervical radicular pain. Ann Rehabil Med. 2011;35(6):826-832. doi:10.5535/arm.2011.35.6.826

50. Cohen SP, Sireci A, Wu CL, Larkin TM, Williams KA, Hurley RW. Pulsed radiofrequency of the dorsal root ganglia is superior to pharmacotherapy or pulsed radiofrequency of the intercostal nerves in the treatment of chronic postsurgical thoracic pain. Pain Physician. 2006;9(3):227-235. 
51. Ding Y, Li H, Hong T, Zhao R, Yao P, Zhao G. Efficacy and safety of computed tomography-guided pulsed radiofrequency modulation of thoracic dorsal root ganglion on herpes zoster neuralgia. Neuromodulation. 2019;22(1):108-114. doi:10.1111/ner.12858

52. Kim ED, Lee YI, Park HJ. Comparison of efficacy of continuous epidural block and pulsed radiofrequency to the dorsal root ganglion for management of pain persisting beyond the acute phase of herpes zoster. PLoS One. 2017;12(8):e0183559. doi:10.1371/journal.pone.0183559

53. Martin S, Hadjipavlou G, Garcia Ortega R, et al. The importance of the location of dorsal root ganglion stimulator electrodes within the nerve root exit foramen. Neuromodulation. 2019.

54. Lee DG, Ahn SH, Lee J. Comparative effectivenesses of pulsed radiofrequency and transforaminal steroid injection for radicular pain due to disc herniation: a prospective randomized trial. $J$ Korean Med Sci. 2016;31(8):1324-1330. doi:10.3346/jkms.20 16.31.8.1324

55. Kim SJ, Park SJ, Yoon DM, Yoon KB, Kim SH. Predictors of the analgesic efficacy of pulsed radiofrequency treatment in patients with chronic lumbosacral radicular pain: a retrospective observational study. J Pain Res. 2018;11:1223-1230. doi:10.2147/JPR.S164414

56. Yoon YM, Han SR, Lee SJ, Choi CY, Sohn MJ, Lee CH. The efficacy of pulsed radiofrequency treatment of cervical radicular pain patients. Korean J Spine. 2014;11(3):109-112. doi:10.14245/kjs.2014.11.3.109

57. Tsou HK, Chao SC, Wang CJ, et al. Percutaneous pulsed radiofrequency applied to the L-2 dorsal root ganglion for treatment of chronic low-back pain: 3-year experience. J Neurosurg Spine. 2010;12(2):190-196. doi:10.3171/2009.9.SPINE08946

58. Lee DG, Cho YW, Ahn SH, Chang MC. The effect of bipolar pulsed radiofrequency treatment on chronic lumbosacral radicular pain refractory to monopolar pulsed radiofrequency treatment. Pain Physician. 2018;21(2):E97-E103.

59. Van Boxem K, Huntoon M, Van Zundert J, Patijn J, van Kleef M, Joosten EA. Pulsed radiofrequency: a review of the basic science as applied to the pathophysiology of radicular pain: a call for clinical translation. Reg Anesth Pain Med. 2014;39(2):149-159. doi:10.1097/ AAP.0000000000000063

60. Bing N, Yonsheng H, Wei T, Wei S, Hongwei Z. Dorsal root entry zone lesion for neuropathic pain due to thoracolumbar spine fracture: long-term result. World Neurosurg. 2019;125:e1050-e1056. doi:10. 1016/j.wneu.2019.01.242

61. Takai K, Taniguchi M. Modified dorsal root entry zone lesioning for intractable pain relief in patients with root avulsion injury. $J$ Neurosurg Spine. 2017;27(2):178-184. doi:10.3171/2017.1.SPINE16234
62. Ko AL, Ozpinar A, Raskin JS, Magill ST, Raslan AM, Burchiel KJ. Correlation of preoperative MRI with the long-term outcomes of dorsal root entry zone lesioning for brachial plexus avulsion pain. J Neurosurg. 2016;124(5):1470-1478. doi:10.3171/2015.2. JNS14\2572

63. Awad AJ, Forbes JA, Jermakowicz W, Eli IM, Blumenkopf B, Konrad P. Experience with 25 years of dorsal root entry zone lesioning at a single institution. Surg Neurol Int. 2013;4(1):64. doi:10.4103/ 2152-7806.112182

64. Zhang XH, Li YJ, Hu YS, Tao W, Zheng Z. Dorsal root entry zone coagulation for treatment of deafferentation pain syndromes. Chin Med J (Engl). 2008;121(12):1089-1092.

65. Sindou M, Mertens P, Wael M. Microsurgical DREZotomy for pain due to spinal cord and/or cauda equina injuries: long-term results in a series of 44 patients. Pain. 2001;92(1-2):159-171. doi:10.1016/ S0304-3959(00)00487-5

66. Samii M, Bear-Henney S, Ludemann W, Tatagiba M, Blomer U. Treatment of refractory pain after brachial plexus avulsion with dorsal root entry zone lesions. Neurosurgery. 2001;48(6):1269-1275.

67. Kumagai Y, Shimoji K, Honma T, et al. Problems related to dorsal root entry zone lesions. Acta Neurochir (Wien). 1992;115(3-4):71-78. doi:10.1007/BF01406361

68. Young RF. Clinical experience with radiofrequency and laser DREZ lesions. $J$ Neurosurg. 1990;72(5):715-720. doi:10.3171/jns.1990. 72.5.0715

69. Campbell JN, Solomon CT, James CS. The hopkins experience with lesions of the dorsal horn (Nashold's operation) for pain from avulsion of the brachial plexus. Appl Neurophysiol. 1988;51(2-5):170-174.

70. Garcia-March G, Sanchez-Ledesma MJ, Diaz P, et al. Dorsal root entry zone lesion versus spinal cord stimulation in the management of pain from brachial plexus avulsion. Acta Neurochir Suppl (Wien). 1987;39:155-158.

71. Thomas DG, Sheehy JP. Dorsal root entry zone lesions (Nashold's procedure) for pain relief following brachial plexus avulsion. J Neurol Neurosurg Psychiatry. 1983;46(10):924-928. doi:10.1136/ jnnp.46.10.924

72. Richter HP, Seitz K. Dorsal root entry zone lesions for the control of deafferentation pain: experiences in ten patients. Neurosurgery. 1984;15(6):956-959.

73. Yabuki S, Kikuchi S. Positions of dorsal root ganglia in the cervical spine. An anatomic and clinical study. Spine (Phila Pa 1976). 1996;21(13):1513-1517. doi:10.1097/00007632-199607010-00004
Journal of Pain Research

\section{Publish your work in this journal}

The Journal of Pain Research is an international, peer reviewed, open access, online journal that welcomes laboratory and clinical findings in the fields of pain research and the prevention and management of pain. Original research, reviews, symposium reports, hypothesis formation and commentaries are all considered for publication. The manuscript management system is completely online and includes a very quick and fair peer-review system, which is all easy to use. Visit http:// www.dovepress.com/testimonials.php to read real quotes from published authors. 